\title{
Los partidos monárquicos en Vizcaya durante la Segunda República
}

\author{
Javier Real Cuesta \\ Catedrático de Historia Contemporánea \\ Universidad de Deusto
}

Recibido: 03.04 .09

Aceptado: 04.05 .09

\begin{abstract}
Resumen: Los liberales monárquicos vizcaínos, vinculados con la burguesía industrial, consiguieron controlar la representación política de la provincia durante el largo período de la Restauración gracias al uso de su poder económico e influencia social. Pero el desarrollo del nacionalismo, del socialismo, el aumento de la conflictividad social, la crisis del sistema de gobierno, condicionaron dicha hegemonía, y orientaron su ideología hacia posiciones antiliberales y autoritarias. La República acentuó y radicalizó dichas tendencias. En el presente artículo se pretende mostrar el proceso seguido, los condicionantes y los componentes: al principio, enarbolaron la bandera del catolicismo, pero luego añadieron otras como el antimarxismo, la crisis de autoridad, el rechazo de la democracia, el antiseparatismo, hasta desembocar finalmente en posiciones antiliberales extremas, sin posibilidad alguna de acuerdo o consenso con otras opciones políticas.
\end{abstract}

Palabras clave: partidos políticos, monárquicos, II República, Vizcaya, antiliberalismo.

Abstract: The liberal monarchical movement of Vizcaya, together with the industrial bourgeoisie, achieved the control of political representation in the Vizcaya Province. This was possible, thanks to the use they made of the social influence and the economic power they held during the long period of the "Restauración» of the Spanish monarchy. However, the development of nationalism, socialism, the increase of social unrest and the crisis in the system of government, influenced their hegemony and oriented their ideology towards anti-liberal and authoritarian positions. In addition, the arrival of the Republic radicalized this tendency. The following article attempts to explain what this process was like, its determining factors and its components. At the beginning, they present themselves as the defenders of the Catholic Church. However, in time, they embraced other views such as the anti-Marxist, anti-separatist attitudes, the authoritarian crisis and the rejection of democracy. These resulted in extreme anti-liberal positions, which offered no possibility of agreement and consensus with the other political parties. lism.

Key words: political parties, monarchists, II República, Vizcaya, anti-libera-

Sumario: INTRODUCCIÓN.-I. ANTES DE LA REPÚBLICA: CARACTERES Y EVOLUCIÓN DEL MONARQUISMO LIBERAL. 1. Hacia una Nueva Derecha en España. 2. El camino hacia el autoritarismo y el antinacionalismo en Vizcaya. 3. El monarquismo destruido.- 
II. LA REPÚBLICA. 1. Las elecciones de Abril de 1931. 2. Catolicismo y neotradicionalismo, primeras señas de identidad ante la República. 3. La incorporación del antiseparatismo al ideario de la derecha. 4. Un sector de centro en el seno de la derecha. 4.1. Derecha Vasca Autónoma.- CONCLUSIONES.

\section{Introducción}

En España la situación de las derechas durante la Segunda República ha sido objeto de numerosos trabajos de manera que nuestro conocimiento sobre ellas es hoy excelente. En especial los estudios de Julio Gil y Pedro Carlos González Cuevas analizan minuciosamente la evolución, ideología, organización, componentes y estrategias de las distintas corrientes que se manifestaron en su seno. Resulta destacable en ellos la atención con la que han estudiado la cuestión que nos parece mas relevante, esto es, el proceso de transformación desde una derecha liberal que operaba en el marco político de la Restauración, una democracia liberal y burguesa a pesar de sus muchas deficiencias, hasta una derecha autoritaria y antiliberal. Se trató por supuesto de un cambio común, muy parecido al que siguió en otros países de Europa. No incluyen en ellos al tradicionalismo, un sector de la derecha que no tuvo que realizar cambio alguno en sus posiciones antiliberales iniciales ${ }^{1}$.

En el ámbito del País Vasco, por el contrario, nuestro conocimiento de este sector político es muy limitado por razones comprensibles. De una parte, la fuerza y el papel central que desempeñó el nacionalismo, y que también ahora tiene, han atraído el interés de los historiadores hacia él, muy superior al manifestado hacia otros partidos, tanto de la derecha como de la izquierda ${ }^{2}$. Por otro lado, las fuentes han condicionado también los estudios, pues mien-

${ }^{1}$ Gil Pecharromán, Julio: Sobre España inmortal, solo Dios. Jose M. ${ }^{a}$ Albiñana y el Partido Nacionalista Español (1930-1937). UNED, Madrid, 2000. Conservadores subversivos: la derecha autoritaria alfonsina (1913-1936). Eudema. Madrid, 1994. Renovación Española. Una alternativa monárquica a la Segunda República Universidad Complutense de Madrid. Madrid, 1985.

GonzÁlez Cuevas, Pedro Carlos: Acción Española: Teología política y nacionalismo autoritario en España. Tecnos. Madrid, 1998. Perfil ideológico de la derecha española: (Teología política y orden social en la España Contemporánea). Tesis Doctoral. Universidad Complutense de Madrid, 1993.

${ }^{2}$ Granja, José Luis: Nacionalismo y II República en el País Vasco. CIS, Madrid, 1986. Este autor ha publicado después gran cantidad de artículos. También en Álava, PABLO, Santiago de: El nacionalismo vasco en Álava (1907-1936). Idatz Ekintza, Bilbao, 1988. PaBlo Santiago de; MEES, Ludger: El péndulo patriótico: historia del PNV (1885-2005). Crítica, Barcelona, 2005. 
tras son numerosas sobre el nacionalismo, la penuria es evidente en el caso de la derecha, al no disponer de organizaciones estables y continuadas.

Así se explica que solo dispongamos de un único trabajo sobre esta durante la Segunda República. Pero resulta genérico y global, sin modulación temporal, seguramente por las razones apuntadas ${ }^{3}$. No obstante, conocemos mejor la situación de este sector en los años anteriores, entre 1917 y 1931, gracias al estudio de Arana Pérez 4 .

Tenemos el propósito de realizar un estudio mas amplio y con fuentes mas precisas sobre el monarquismo en Vizcaya durante este período, pero en el presente artículo pretendemos analizar el proceso de definición ideológica, un discurso sometido a cambios, modulado por los acontecimientos, diferente de sus correligionarios de otras regiones o de Madrid, e influido sobre todo por la presencia del nacionalismo, un movimiento que compitió por la hegemonía en el seno la derecha. Utilizamos para ello El Pueblo Vas$c o$, algo mas que un periódico pues no solo informaba, acogía las opiniones, etc., sino que, ante la inexistencia de organizaciones estables, se constituía en representante en todos los aspectos, impulsando la organización y marcando la línea política e ideológica. A pesar de su vinculación a la corriente mas radical, nunca dejó de estar abierto y atento a las demás. Sus informaciones acerca de la política del Gobierno era minuciosa y en sus páginas tuvieron acogida los principales dirigentes e intelectuales de la derecha española: Salaverría, Basterra, Adán, Maeztu, Calvo Sotelo, Gil Robles, Sánchez Mazas, Balparda, sin contar con los adscritos al catolicismo y el tradicionalismo como Bilbao, Pradera, etc. Una influencia que sobrepasaba el marco local ${ }^{5}$.

\section{Antes de la República: caracteres y evolución del monarquismo liberal}

\section{Hacia una Nueva Derecha en España}

La derecha autoritaria alfonsina, una de las corrientes mas activas y beligerantes de la Segunda República española, representa la culminación de un proceso de transformación ideológica iniciado a comienzos del siglo y desarrollado sin interrupción en las décadas siguientes. Del liberalismo conservador, representado por partidos dinásticos que actúan durante el régimen de la Restauración, al autoritarismo, el tradicionalismo y, en definitiva, el anti-

${ }^{3}$ Plata PARGa, Gabriel: La derecha vasca y la crisis de la democracia española, 19311936. Diputación Foral de Vizcaya. Bilbao, 1991. A pesar del título, el estudio se refiere solo a Vizcaya.

${ }^{4}$ ARANA PÉREZ, Ignacio de Loyola: El monarquismo en Vizcaya durante la crisis del reinado de Alfonso XIII, 1917-1931. Eunsa, Pamplona, 1982.

${ }^{5}$ Sobre El Pueblo Vasco, ver Pablo, Santiago de: La prensa vasca durante la Segunda República. Eunsa, Pamplona, 1992 y Plata PARGa, Gabriel: op. cit. 
liberalismo; de la derecha decimonónica a la Nueva Derecha. Los trabajos de González Cuevas y Julio Gil ya señalados explican esta transformación incluyéndola además dentro de un proceso general que afecta a toda la derecha liberal europea. «En el caso español -señala Gil-, la Nueva Derecha española nació en torno a los años de la Gran Guerra, con una o dos décadas de retraso con respecto a sus homónimas europeas, lo que explica su debilidad orgánica y lo tardío de la concreción de su corpus doctrinal...» ${ }^{6}$.

El primer eslabón del cambio fue el Partido Maurista que, al someter a revisión profunda los valores liberales del conservadurismo a favor del autoritarismo, constituirá el «grupo principal de la Nueva Derecha española», y su rama juvenil, «el primer eslabón de la derecha autoritaria alfonsina». Los sucesos de 1917 acelerarían esta tendencia no solo en el seno del maurismo sino, en la opinión de otros sectores liberal-conservadores, al tomar conciencia de que el auge del sindicalismo y grupos revolucionarios exigían soluciones autoritarias, de fuerza, para mantener el orden social y político. En 1923 era evidente el fracaso del discurso y la práctica política mantenidos por los partidos dinásticos liberales tradicionales para hacer frente a estos retos ${ }^{7}$.

La Dictadura fue un nuevo paso en el refuerzo de las tendencias autoritarias. Ante los síntomas de agotamiento del régimen, muchos pensaron que era necesario un Estado de nuevo cuño para afrontar los cambios sociales y políticos. La creación de la Unión Patriótica durante la Dictadura aceleró el rearme ideológico de la derecha aportando a su acervo doctrinal tanto el pensamiento tradicional hispano como el de la derecha moderna autoritaria europea: democracia orgánica, Estado corporativo, nacionalismo, religión, orden, familia y autoridad ${ }^{8}$.

\section{El camino hacia el autoritarismo y el antinacionalismo en Vizcaya}

En el País Vasco, la vida política durante el período de la Restauración discurrió por cauces diferentes del resto de España por la existencia de un sistema de partidos propio. Tradicionalismo y liberalismo habían sido dos ideas-fuerza sobre las cuales se articularon las distintas corrientes políticas desde antes incluso de 1876, constituyendo dos bloques enfrentados. El carlismo, el catolicismo integrista y otros grupos antiliberales eran fuerzas poderosas que contaban con importantes apoyos en la sociedad vasca; enfrente, los principios liberales constituían la base esencial de identidad de

\footnotetext{
${ }^{6}$ GIL, Julio: Conservadores subversivos..., Eudema. Madrid, 1994. p. 5.

${ }^{7} \mathrm{La}$ inestabilidad de los Gobiernos, el fraccionamiento de los partidos, las huelgas, disturbios sociales, movimientos en el ejército, etc., caracterizaron estos años como de agotamiento del régimen. Ver FonTANA, Joseph; VillaREs. Ramón: La época del liberalismo, en $H .^{a}$ de España. Crítica, Barcelona, 2008.

${ }^{8}$ Ver GIL, Julio: Conservadores... p. 49 y ss.
} 
los partidos dinásticos, republicanos y socialistas. No obstante, no se trataba solo de principios sino también de símbolos, sentimientos y emociones personales construidos en torno a una guerra civil cuyas heridas siguieron estando presentes. En una fecha tan lejana como 1913, así lo reconocía el conde de Romanones: «Vuestro liberalismo está forjado a base de engaños, está aquilatado por las contrariedades y los sacrificios; por eso es aún mas fuerte que el nuestro; en muchos de vosotros su partida de bautismo está escrita con sangre (...). El liberalismo tiene aquí raíces profundas y seculares» ${ }^{9}$. Hasta 1907 fueron estas las pautas a las que se ajustó la vida política local.

Desde 1903, el desarrollo del nacionalismo por un lado, una corriente ajena a estas ideas-fuerza, y del socialismo por otro, modificó las bases referidas y se realizaron entonces distintos ensayos encaminados a la formación de bloques de poder sobre nuevas bases Así, entre 1903 y 1907, la defensa de la Religión, fue la base sobre la que se articuló un bloque «católico» compuesto por carlistas, integristas, nacionalistas y algunos individuos procedentes del campo liberal-conservador, frente a otro liberal-democrático. Precisamente durante la República esta alianza sería recordada para justificar el acercamiento de los dinásticos a los tradicionalistas. Pero fue a partir de 1909 cuando el cambio tuvo mayor duración y en este caso no fue el liberalismo ni la religión sino la cuestión social la idea en torno a la cual se articularon las distintas fuerzas políticas a fin de formar los respectivos bloques. A un lado los defensores del orden, la religión y la sociedad, y al otro los revolucionarios. «Nuestros enemigos -decía en 1911 el dirigente conservador Jose María Ibarra-, son los republicanos y socialistas» ${ }^{10}$. Derecha e izquierda constituirían desde entonces una nueva bipolaridad. El bloque de izquierdas quedaría conformado por republicanos y socialistas junto a dinásticos avanzados. En el bloque de derechas se ubicaban los carlistas, católicos, nacionalistas y los conservadores monárquicos. Y también durante la República muchos recordaron con nostalgia estas coaliciones ${ }^{11}$.

Desde 1917 las ideas-fuerza derecha-izquierda fueron sustituidas por la cuestión nacionalista, de manera que nacionalismo-antinacionalismo constituirán los ejes de una nueva dinámica bipolar. Españolismo frente a nacionalismo. En consecuencia, cambian las alianzas. Dinásticos, socialistas y, en menor medida, republicanos configuraron el bloque antinacionalista frente a nacionalistas y algunos sectores carlistas y católicos. Aludimos a estos precedentes para hacer ver cómo los liberales dinásticos habían pasado por cir-

${ }^{9}$ «Discurso». La Voz de Guipúzcoa, 23 de septiembre de 1913.

${ }^{10}$ YbarRa, Javier: Política nacional en Vizcaya, IEP. Madrid, 1947, p. 377.

${ }^{11}$ Real Cuesta, Javier: Partidos, elecciones y bloques de poder en el País Vasco. 18761923. Universidad de Deusto. Bilbao, 1991. Cap. 1.․ Debemos resaltar que, especialmente en el campo de la derecha, las uniones fueron siempre electorales, precarias e incompletas por la dificultad de integrar a los nacionalistas. 
cunstancias muy distintas, lo que les obligó a adoptar discursos diferentes: anticarlismo primero, seguido de catolicismo, autoritarismo y antinacionalismo.

Los partidos dinásticos liberales estuvieron escasamente organizados durante este período. Estaban representados por grupos o individuos pertenecientes a la oligarquía e interesados en obtener el poder en los órganos locales, ayuntamientos y, sobre todo, la diputación, a fin de defender sus intereses económicos. Su presencia solo era visible en las elecciones, a las cuales concurrían utilizando su influencia social y capacidad económica. Desde 1897 la famosa «Piña», constituida por individuos de este grupo, concurrió a las elecciones hasta la segunda década del siglo Xx, utilizando hábilmente los resortes caciquiles. No necesitaban disponer de organización alguna estable. A partir de 1907 sin embargo, ante el declive de la Piña, algunos grupos intentaron reorganizar esta corriente sobre nuevas bases: así, Fernando María Ybarra fundaba en 1909 el Partido Conservador, mientras que otros elementos dinásticos mas avanzados constituían el Partido Liberal. En 1914 el Partido Conservador se declaró maurista. En realidad estos cambios fueron mas bien formales pues, a pesar de algunos intentos de los mauristas por constituirse como un partido de masas, lo cierto es que parecen una continuación de la Piña: partidos de notables que actuaban dentro del sistema clientelar tradicional, suficientes para controlar las instituciones representativas: ayuntamientos, diputaciones, y representación al Congreso.

Los éxitos electorales y políticos del nacionalismo a partir de 1917 rompieron esta hegemonía obligándoles a unirse y organizarse para combatirlo. El instrumento en este caso fue la Liga Monárquica (7-1-1919) y la bandera, el españolismo. Como antes, la Liga nacía como un partido de notables, no de masas, vinculado a los grandes industriales y decidido a utilizar toda su influencia y dinero para derrotar al nacionalismo separatista. El éxito acompañaría sus esfuerzos consiguiendo restablecer su hegemonía política en la provincia.

\section{El monarquismo destruido}

La Dictadura aseguró el orden social y político pero destruyó las bases sobre las que los dinásticos habían mantenido tantos años el control político en la provincia ${ }^{12}$ :

1. La disolución de los ayuntamientos y su sustitución por otros sobre nuevas bases, la suspensión de las diputaciones y el nombramiento de personas adictas al nuevo régimen, de delegados gubernativos, la implantación de medidas en el ámbito de la organización judicial, y

${ }^{12}$ ArAna PÉReZ, Ignacio de Loyola: op. cit. En esta obra se analiza ampliamente todo lo referente al impacto de la Dictadura en Vizcaya. 
otras de índoles administrativa, arrancaron las bases caciquiles y clientelares tradicionales de estos grupos.

2. Además, quedaron divididos respecto de la colaboración con la Dictadura pues, aun cuando unos colaboraron de forma entusiasta, otros lo hicieron con recelo y algunos fueron contrarios, como ocurrió en los casos de Balparda y Orueta (en general, el sector mas avanzado de los liberales dinásticos).

3. Las organizaciones monárquicas, Liga Monárquica, partido maurista, Juventud, no se disolvieron, pero quedaron vacíos de contenido y actividad al quedar subordinadas a la organización partidista impulsada por la Dictadura, Unión Patriótica.

4. Pero lo mas grave fue el vaciamiento ideológico que provocó el apoliticismo del régimen, la falta de soporte ideológico. La UP quedó convertida en una agrupación sin ideología a la que, como instrumento de la Dictadura, debían pertenecer todos aquellos que desempeñasen cargos relacionados con la Administración. En ningún caso conseguiría unir a todos los monárquicos. El proyecto de Constitución fue «... una mezcla híbrida de liberalismo y corporativismo, con ciertas gotas de tradicionalismo» ${ }^{13}$. Fruto de la transacción entre las diversas ideologías conservadoras y autoritarias, el resultado no convenció a nadie. En definitiva, la Dictadura destruyó las bases de la vieja política sobre las que se asentaba la hegemonía de los liberal-dinásticos sin lograr sustituirlas por otras. José Félix de Lequerica entonces, y Areilza después, expresaron su amargura porque la Dictadura había destruido lo anterior sin conseguir imponer otro orden que le permitiera sucederse. Abogaron entonces, especialmente el primero, por construir un nuevo orden sobre la base de la autoridad, un nuevo Estado de corte autoritario, dentro de la Monarquía, como única fórmula para mantener los valores y la sociedad de la Restauración ${ }^{14}$. Lequerica expresaba el sentir de un grupo de intelectuales monárquicos como Basterra, Salaverría, Joaquín Adán, Zuazagoitia, Sánchez Mazas y otros que, aunque de procedencia liberal, habían ido situándose en posiciones autoritarias y antiliberales.

La caída de la Dictadura cogió en Vizcaya a estos elementos divididos, desorganizados, inhibidos y sin posibilidad de utilizar los resortes del poder. La vieja Liga Monárquica, la Juventud y el Círculo Maurista se mantenían vigentes, pero su actividad era nula, solo formal y sin un contenido ideológico claro. Lo primero que hicieron ante los acontecimientos de 1930 fue

${ }^{13}$ En Arana Pérez, Ignacio de Loyola: Ibidem. p. 109, nota 232.

${ }^{14}$ LeQuericA, José Félix de: Soldados y políticos. Voluntad, Madrid, 1929. También PlaTA PARGA, G. op. cit., hace un estudio de sus posiciones doctrinales, p. 30 y ss. 
mirar a las distintas corrientes que dentro de la derecha se manifestaban en esos momentos en España, buscando en ellos las pautas de conducta: a comienzos de año, ante la orfandad en la que quedaron, solo el Partido Maurista y la Liga regionalista parecían tener la capacidad para unirlos. En diciembre de 1930, los regionalistas publicaron un programa político consensuado con los mauristas, Cambó y Gabriel Maura, destinado a servir como carta fundacional de una federación de grupos centristas: Centro Constitucional se denominó.

Esta operación fue vista con esperanza por algunos sectores del monarquismo vizcaíno. Y así, mientras la Liga Monárquica se mantuvo en silencio, el 15 de marzo de 1931 el Círculo Maurista de Bilbao acordó adherirse al Centro $^{15}$. Pero esta opción tuvo poco recorrido, pues seis semanas después de la fundación, la proclamación de la República representó su muerte. Como señala Gil, la posición centrista, liberal, reformista y constitucional que ambos quisieron dar al nuevo partido no era una opción válida para unir la derecha española, compuesta por grupos y corrientes radicalizadas y ajenas a esta orientación ${ }^{16}$.

Otra opción partió de personalidades pertenecientes a la extinta Unión Patriótica: el 24 de marzo quedó constituida en Madrid la Unión Monárquica Nacional y a primeros de abril publicó un Manifiesto. Defendía la obra de la Dictadura pero, por lo demás, manifestaba posiciones moderadas y constitucionales, a pesar de lo cual no fue bien recibida por la derecha conservadora a la vista de las personalidades que la integraban: E. Bilbao, Marcelino Oreja, Joaquín Bau, Maeztu, Gay, Quintanar, Delgado Barreto y otros procedentes del tradicionalismo o el primorriverismo más radical. También los círculos católicos próximos la acogieron con recelo ${ }^{17}$.

Respecto de esta segunda opción no parece que ninguna de las organizaciones existentes en Vizcaya se sumara a ella. Al parecer se constituyó una Junta Provincial nueva, lo cual resulta sorprendente dada la proximidad ideológica de los elementos que en esos momentos dirigían Juventud y la Liga (Lequerica, Areilza, Zubiría, etc.). Lo cierto es que eran movimientos de escaso alcance, ante los cuales El Pueblo Vasco aconsejaría cautela y pacien$\mathrm{cia}^{18}$.

Una tercera opción la representaron distintos grupos muy radicalizados pero con mínima implantación y audiencia. El primero fue Juventud Monárquica, integrada por grupos locales autónomos de jóvenes procedentes de la

15 PV, 16-III-1931. «Asamblea del Círculo Maurista».

${ }^{16}$ GiL, Julio: Conservadores..., p. 70.

${ }^{17}$ Ibidem, p. 95.

${ }^{18}$ VG, 11-V-1931, «Comentarios». Dos días antes UMN de Vizcaya había aconsejado a sus afiliados serenidad «pues estamos a la espera de que las derechas españolas se organicen». PV, 9-11-1931, «A nuestros amigos». 
aristocracia y la burguesía. Más activos y radicales en defensa de la Monarquía ${ }^{19}$, esta opción tendría mayor efecto en el monarquismo vizcaíno pues un grupo de jóvenes, hijos de los más caracterizados y antiguos monárquicos encuadrados en la Liga, reconstruyeron la antigua Juventud Monárquica de Bilbao. Pero, tras unos meses, la organización dejó de funcionar ${ }^{20}$.

Finalmente habría que contar los sectores conservadores incorporados al Gobierno Berenguer, de los cuales desconocemos los existentes en Bilbao pues no estaban organizados.

\section{LA REPÚBLICA}

\section{Las elecciones de abril de 1931}

De modo que, a la vista de las elecciones municipales del 12 de abril, los distintos grupos monárquicos siguieron desorganizados, desorientados y divididos. Sin embargo, el realismo acabaría imponiéndose en las elecciones municipales, ya que en vísperas de los comicios pudieron acordar una coalición compuesta por la UMN, Liga Monárquica, Centro Constitucional y Tradicionalistas, «Candidatura de Concentración Monárquica y de Derechas» ${ }^{21}$, no sin que en ciertos municipios concurrieran divididos (Bermeo). La candidatura no consiguió reagrupar a todos los sectores católicos y de derechas: los nacionalistas y una rama de los tradicionalistas, los jaimistas, presentaron candidaturas propias, mientras que los grupos católicos, a pesar de sus llamamientos a favor de la unidad, se vieron obligados a dispersar el voto entre todas ellas $^{22}$. Esta dispersión será una constante durante los años siguientes y provocará, además, el retraimiento político y electoral de muchos electores.

\section{CAMPAÑA ELECTORAL Y RESULTADOS}

El desánimo por la división es perceptible tanto por la escasa actividad de propaganda, un único mitin en Bilbao el 9 de abril, como por los temas que centraron la campaña. La religión y el orden, la familia, la propiedad; el orden social y la civilización cristiana frente al caos y la «extirpación de la fe religiosa»; la antirrevolución, en definitiva, contra la Revolución. Cuestiones como se ve, generales; nada de alusiones al nacionalismo o separatismo, al parlamentarismo, ni tan siquiera al peligro que afectaba a la Monarquía en

${ }^{19}$ Vegas Latapie, Eugenio: Memorias políticas: el suicidio de la Monarquía y la Segunda República. Planeta. Barcelona, 1983, p. 5.

${ }^{20}$ Plata, p. 70 y ss.

${ }^{21}$ Se constituyó el 29 de marzo. PV, 29-III-1931. El Manifiesto lo publica y analiza ARANA, Ignacio de Loyola: Op. cit. p. 146.

${ }^{22}$ PV, 26-III-1931 a 13-IV-1931. 
el caso de resultados contrarios. Se trataba, por tanto, de principios católicos, conservadores, pero genéricos y comunes, capaces de unir a todo el electorado de derechas y católico.

Los resultados obtenidos en Vizcaya podemos resumirlos en los siguientes aspectos $^{23}$ :

1. En los municipios menores de 6.000 habitantes, los dinásticos mantuvieron la hegemonía al conseguir el $40 \%$ de los concejales. El PNV, el $26 \%$.

2. En Bilbao, al frente siempre de su Ayuntamiento durante la Dictadura, obtuvieron 3 de los 46 concejales (19,2\% de los votantes); por el contrario, el PNV obtendría el 27,6\% y 14 concejales. El Bloque antimonárquico, $49,3 \%$ de los votos y 29 concejales.

¿Cómo valorar estos resultados? En el área rural ponen de manifiesto la pervivencia de las redes tradicionales caciquiles controladas por los monárquicos. En cuanto a Bilbao, sin duda la valoración en términos generales es negativa para aquellos, pero conviene matizarlo mejor. Si analizamos los resultados de las elecciones generales, provinciales y locales durante el período 1903-1923 comprobamos que las fuerzas de centro-izquierda e izquierda eran mayoritarias ${ }^{24}$. De modo que la victoria del Bloque antimonárquico era previsible, incluso podemos decir que el número de votos fue inferior a los que obtuvo en las elecciones celebradas esos años (sobrepasaron el 50\%). Por otro lado, tampoco cabe la sorpresa por los resultados del PNV, pues ya había conseguido porcentajes superiores al $20 \%$ en dichas elecciones. En realidad, el sistema electoral de mayorías ${ }^{25}$ fue lo que condicionó la repartición de los concejales: 29 el Bloque, 14 el PNV y 3 monárquicos (en la elección parcial de 31 de mayo los primeros aumentarían a 31). Mas asombroso fue lo ocurrido en Guecho, municipio en el que vivían muchas de las personalidades más significadas de la corriente monárquica, donde obtuvieron solo 3 de los 21 totales, mientras que el PNV logró ;15! (sobre 19 totales) (debieron existir razones específicas). En el resto de municipios de la margen izquierda también obtuvieron resultados limitados, pero no tanto como en Guecho. Si estas elecciones locales eliminaron su influencia en la capital, más grave fue para ellos la suspensión de las Diputaciones provinciales el 21 de abril y su sustitución por unas Comisiones Gestoras, un

${ }^{23}$ GRANJA, José Luis: El nacionalismo... pp. 105-126.

${ }^{24}$ Ver REAL, Javier: Elecciones ... pp. 174 y 175. Resulta difícil analizar los resultados por la diversidad de coaliciones y condiciones que se formaron, pero la tendencia es la que apuntamos.

${ }^{25}$ El Bloque obtuvo mayoría en 9 de los 10 distritos. El sistema electoral venía regulado por la Ley 8-VIII-1907. Estaba basada en distritos plurinominales con mayorías corregidas. Art. 21. 
cambio que el Gobierno realizó con carácter provisional, pero que se mantendría vigente durante toda la República ${ }^{26}$. Fue una medida cuya importancia no ha sido resaltada suficientemente por la bibliografía actual, pero que el Gobierno sí tuvo clara desde el principio: eliminar una institución dotada de un poder muy superior a las del resto de España, controlada por los dinásticos y desde la cual habían ejercido su influencia en la Restauración tanto en el plano provincial como nacional.

Si a ello añadimos el desencanto por el apoyo de una parte del electorado católico y de derechas al PNV, así como los acontecimientos de carácter general que el triunfo de las fuerzas favorables a la República desencadenaron, proclamación de la República, caída de la Monarquía, podemos comprender el desánimo, el desconcierto, la desorganización tan profunda, la orfandad en la que estuvieron sumidos durante mucho tiempo. Era urgente encontrar un nuevo discurso capaz de reagrupar la opinión de las derechas ante los cambios que iban produciéndose con rapidez en estos meses, algo realmente difícil cuando había otras corrientes poderosas como los católicos independientes y los nacionalistas con mayor capacidad de atracción.

\section{Catolicismo y neotradicionalismo, primeras señas de identidad ante la República}

Desde el punto de vista organizativo, al igual que en Madrid, aquí también se produjo la desbandada de la que tan amargamente hablarían después. La Liga Monárquica, aunque vigente, quedó desaparecida; el Círculo Maurista, después de la desaparición del Centro, se disuelve y, para facilitar la reunificación de las fuerzas monárquicas, aconseja a sus afiliados incorporarse a Juventud Monárquica (JM); finalmente, una «Junta provincial» de la UMN publica un comunicado que sugiere serenidad a sus militantes a la espera de que las derechas españoles se organizaran ${ }^{27}$.

La orfandad ideológica de los alfonsinos, su desorganización, otorgaron a la prensa afín un importante papel como orientadora de la opinión adicta. El Pueblo Vasco, órgano del conservadurismo desde 1910, del maurismo después y defensor de la Dictadura, asumiría durante la República el papel de analista político, aglutinante y guía ideológico de los núcleos conservadores y españolistas de Vizcaya, sus propietarios fueron los hermanos Gabriel M. ${ }^{\mathrm{a}}$ y Fernando de Ybarra, miembros de una familia perteneciente a la más

\footnotetext{
${ }^{26}$ Para todo lo relacionado con el Estatuto, ver GRANJA, pp. 277-307.

27 «Algunos correligionarios se nos han acercado para pedirnos orientación y consejo en estos momentos de incertidumbre. Esta determinación es bien explicable después del mes transcurrido desde las elecciones municipales, y si no hemos señalado la del partido es porque para estas fechas esperábamos que hubieran salido de esta situación expectante las derechas españolas y definido su actitud para atemperar el nuestro...», PV, 9-V-1931, «Comentarios del día».
} 
genuina oligarquía vizcaína). Aunque mantuvo inalterable su apoyo a la Monarquía desterrada, nunca cejó en el propósito de aglutinar todas las corrientes de la derecha, desde las más intransigentes con la República como el tradicionalismo, hasta las accidentalistas representadas por la CEDA, sin olvidar el catolicismo independiente. Pronto se convirtió en uno de los principales referentes ideológicos, acogiendo a la mayoría de propagandistas, escritores e intelectuales de la derecha española.

Tras el 12 de abril, el periódico, angustiado por los sucesos de estos días, reafirma su apoyo a la Monarquía: «Nosotros en nuestro puesto...» ${ }^{28}$, al tiempo que manifiesta la aceptación del régimen, «siempre que la República muestre cordura», el rechazo de la violencia y el propósito de trabajar dentro de la legalidad de manera activa, frente a algunas voces que se inclinaban por la abstención ${ }^{29}$. Igualmente se identifica con Rafael Aizpún, navarro que después militaría en la CEDA, en la necesidad de no de conspirar, sino de hacer política ${ }^{30}$. Finalmente, se adhiere a la presentación de Acción Nacional, en cuyo acto rechazan expresamente la utilización de la fuerza y defienden el uso de la legalidad constitucional o republicana ${ }^{31}$.

Pero los acontecimientos que se producen hasta finales de año provocan una radicalización en sus posiciones ideológicas y políticas. La política del Gobierno, los cambios en el ejército, en la instrucción pública, en economía, el nombramiento de las Gestoras, etc., suscitan editoriales o comentarios de protesta y perplejidad ${ }^{32}$. Pero es sin duda la política religiosa la que provoca las reacciones más airadas y amargas, una cuestión que, como se ha señalado reiteradamente, es indudable que exacerbó los sentimientos de los católicos en general y de los monárquicos en particular. «Nos acongoja, nos produce una inmensa amargura», señala El Pueblo Vasco al conocer la separación Iglesia-Estado en el proyecto de Constitución ${ }^{33}$.

${ }^{28} \mathrm{PV}, 18-\mathrm{IV}-1931$, «Nosotros en nuestro puesto».

${ }^{29}$ PV, 24-V-1931, «Comentarios». Ante un artículo de Juan Pujol favorable al abstencionismo de la derecha, PV se manifiesta a favor de la intervención en la lucha electoral y la defensa de sus principios dentro de la legalidad. «Discrepando de nuestro ilustre colaborador, nosotros somos enemigos de la abstención y propugnamos por una entusiasta intervención de las derechas en la lucha electoral y en defensa de sus principios, siempre dentro de la más escrupulosa legalidad».

${ }^{30}$ PV, 29-IV-1931, «Propósitos monárquicos».

${ }^{31}$ PV, 3-VI-1931, «Primer mitin de Acción Nacional».

${ }^{32} \mathrm{PV}, 10-\mathrm{V}-1931$, «En plena e insolente dictadura» denuncia los atropellos del Gobierno en el ejército, instrucción, economía y otras materias. PV, 23-V-1931: «Nuestro voto en contra» por el decreto que establece la libertad de cultos.

${ }^{33} \mathrm{PV}, 14-\mathrm{X}-1931$, «Contra la descatolización de España»: «La separación de la Iglesia y del Estado, si como católicos nos acongoja, no deja de producirnos como españoles honda amargura (...), esta medida va contra la tradición interrumpe el curso de la historia...». 
Al mismo tiempo, en el ámbito local los acontecimientos los colocaron en una posición subordinada y marginal. El proyecto de Estatuto impulsado

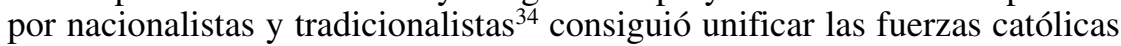
y de la práctica totalidad de la derecha, pero los monárquicos se limitaron a sumarse a este sin participar activamente: «Es la manifestación de la voluntad de la mayoría de un país, y es sobre todo, por donde en estos momentos marchamos todos los vascos de la derecha...». ${ }^{35}$ Durante los meses de mayo y junio son muy escasas las referencias del periódico acerca del proceso estatutario y se limita a resaltar tan solo «el catolicismo que impregna el Estatuto ${ }^{36}$. Fue seguramente un apoyo obligado por la incorporación de los tradicionalistas $^{37}$. Igual sucede con las elecciones constituyentes de junio, en las cuales la única organización subsistente que se manifestó en el campo monárquico, JM, dió su apoyo a la candidatura pro-Estatuto pero no realizó campaña alguna de propaganda ${ }^{38}$. Igualmente mantienen un discreto silencio sobre la actitud y posiciones del PNV. En definitiva, durante todo el año 1931, los monárquicos vizcaínos continuaron desorganizados ${ }^{39}$, retraídos ${ }^{40} \mathrm{y}$ desconcertados, y quedan al margen de un movimiento político de tanto calado en el País Vasco como fue el Estatuto de Estella.

La aprobación de la Constitución en diciembre y las vicisitudes del proceso estatutario (fracaso del Estatuto de Estella y puesta en marcha de un nuevo Estatuto a cargo de las Gestoras) les permitió definir mejor su discurso ideológico y adoptar una táctica mas definida. A partir de este momento, El Pueblo Vasco, al tiempo que promueve la reorganización, opta ya por una orientación ideológica y táctica más definida cuyo contenido fue señalado por Ramón Sierra, Presidente de JM, quien pronunció un discurso en el Círculo Tradicionalista de Bilbao el 27 de diciembre: se trata de un discurso en el que resume las líneas futuras de actuación de la derecha ${ }^{41}$.

${ }^{34}$ Beobide, Ignacio M. ${ }^{\text {a: }}$ «Prieto y la autonomía vasca: un problema de Estado». Estudios de Deusto. Vol. XXX (enero-junio). Bilbao, 1982. pp. 9-70. «El Estatuto de la Libertad». Estudios de Deusto. Vol. XXIX. Bilbao, 1981. GranJA, op.cit. pp. 373-397.

${ }^{35} \mathrm{PV}, 26-\mathrm{IX}-1931$, «Comentarios del día».

${ }^{36}$ PV, 28-IX-1931, «Comentarios del día».

${ }^{37}$ Lo cierto es que, como indicamos, el Estatuto de Estella no fue objeto de análisis por los dirigentes o ideólogos monárquicos, quizás porque se hizo al margen de ellos y porque recelaban de su posible instrumentación por los nacionalistas.

${ }^{38} \mathrm{JM}$ recomienda esta candidatura, PV, 25-VI-1931.

${ }^{39}$ Plata, G.: La derecha..., pp. 70-74. Solo Juventud Monárquica aglutinaba un escaso número de jóvenes pertenecientes a la oligarquía tradicional, entre los que destacan Jose M. ${ }^{\text {a }}$ Areilza, el marqués de Mudela, Castiella, Zubiría y otros.

${ }^{40}$ González Cuevas, Juan P.: Acción Española..., p.148 y ss. Como ejemplo de ese retraimiento me parece significativo señalar el hecho de que solo figure un vizcaíno en los comienzos de Acción Española, Jose M. ${ }^{a}$ de Areilza, lo cual contrasta con el apoyo generalizado de la burguesía en 1935.

${ }^{41}$ PV, 28 diciembre 1931, «Discurso en el Círculo Tradicionalista». 
Después de constatar el resurgimiento de las derechas del estupor que les produjo el resultado de las elecciones de abril, señala la necesidad de encauzar dicha reacción. Para ello, dice, «es preciso que dejemos claramente delimitado el campo de las derechas, fijando bien qué es lo que entendemos por derechas y qué partidos pueden quedar comprendidos dentro de esta clasificación». Excluye a los radicales de Lerroux, también a la Derecha Liberal Republicana, y respecto de los nacionalistas, su posición es mas matizada pues, en principio, les excluye de este campo al apoyar estos el Estatuto de las Gestoras, si bien deja la puerta abierta a una colaboración con ellos al señalar que «siempre que las autoridades de la Iglesia indiquen la conveniencia de una unión de todos los católicos, yo no tengo inconveniente en luchar unido a los nacionalistas...». Son entonces los tradicionalistas y los católicos partidiarios de la dinastía alfonsina los que constituyen la derecha. En cuanto a los principios a los que se siente vinculado, señala que son los mismos que profesa el tradicionalismo: Dios, Patria, Fueros y Rey; e igualmente rechaza la soberanía de las Cortes, el sufragio universal, la división de poderes y la libertad religiosa. A la vista de tales afirmaciones cabe decir que este sector continúa y profundiza en la deriva autoritaria y antiliberal que algunos individuos habían manifestado durante la Dictadura.

Lo cierto es que El Pueblo Vasco en los meses anteriores ya se había mostrado muy próximo al sector tradicionalista, al recoger mítines y actos de propaganda y dar cabida en sus páginas a significados miembros de este partidiarios de la unidad de acción con los alfonsinos como Esteban Bilbao, Víctor Pradera y, de manera especial, Marcelino Oreja. Pero desde estas fechas y durante la primer mitad del año siguiente, sigue esta orientación de manera más clara y decidida, al tiempo que alienta a la organización de este sector $^{42}$ : «Las derechas debieran organizar una amplia concentración de todos los católicos en torno a un programa mínimo» ${ }^{43}$. Pero los llamamientos obtienen escaso eco, pues durante el año no dan muestras de organización y también su actividad pública es muy reducida. Tan solo el 25 de abril celebran, por vez primera desde abril de 1931, un mitin multitudinario organizado por Pilar Careaga, presidenta de una reciente «Agrupación de Defensa Femenina», en el cual interviene José M. ${ }^{a}$ Pemán como orador único. Insta a la unidad de las derechas en torno a religión, familia, orden, enseñanza y propiedad, principios atacados por la Revolución ${ }^{44}$. Salvo Careaga, y Areilza

\footnotetext{
${ }^{42}$ PV, 29-XII-1931, «Hay que actuar». Al día siguiente del discurso de Sierra, El Pueblo Vasco, en referencia al acto, «saluda el movimiento de reacción y propaganda de las derechas», al tiempo que emplaza a los monárquicos a organizarse, «hay que organizarse pronto, coordinar esfuerzos y orientaciones urgentemente».

${ }^{43} \mathrm{PV}, 14-\mathrm{II}-1932$, «La unión de los católicos».

${ }^{44}$ PV, 26-IV-1932, «Acto de propaganda de Acción de Defensa Femenina en el frontón Euskalduna».
} 
no hay en Vizcaya dirigentes que den señales de actividad, quizás porque la mayoría consideró mas factible intentar derribar la República por la fuerza, por lo cual apoyan con dinero la formación en Bilbao del Partido Nacionalista Español ${ }^{45}$, la Sanjurjada en agosto (registro en el Círculo Monárquico de Las Arenas; Areilza y Oriol estuvieron al tanto de la sublevación y Lequerica y Maeztu estuvieron detenidos unos días acusados de participación). También en los meses siguientes miembros significados de la oligarquía vasca participaron en la financiación de distintas conspiraciones de la derecha ${ }^{46}$.

Los alfonsinos locales, al tiempo que apoyan las conspiraciones, siguen con atención las evoluciones de las distintas corrientes de la derecha española. Gil Pecharromán analiza al detalle este proceso del cual nos interesa resaltar aquí, por un lado, la inclusión de la corriente alfonsina en Acción Popular, dirigida por sectores católicos sociales partidiarios de una política accidentalista respecto de la República, y, por otro, sus esfuerzos por articularse y organizarse como partido específicamente alfonsino. El plan consistía en crear un gran partido que fundiese a los diversos sectores alfonsinos para establecer luego una alianza con la Comunión Tradicionalista y, desde una posición de fuerza, negociar el pacto federativo con los accidentalistas. A lo largo de los meses de enero y febrero de 1933 quedaría constituido el nuevo partido, denominado Renovación Española (RE).

Algunas organizaciones locales que habían girado en la órbita de Acción Popular se sumaron a esta tercera fuerza, entre ellas Juventud Monárquica de Bilbao, una organización presidida por Ramón Sierra primero y el marqués de Mudela después, cuya figura mas activa era Jose M. ${ }^{\mathrm{a}}$ de Areilza. Contaba en estos momentos con unos 200 afiliados, pertenecientes en su gran mayoría a las familias acomodadas de Bilbao y Guecho: Evaristo Churruca, Lorenzo Vilallonga, Alfonso Alcalá Galiano, Gabriel Zubiría, Pilar Careaga, Francisco Igartua, José Manuel Escauriaza, Fernando Castiella y otros. La Juventud era el único órgano visible de los alfonsinos locales, pero su actividad había sido limitada y puntual. A partir de ahora dio muestras de mayor actividad al impulsar algunos mítines, misas, conferencias y concursos literarios, pero dentro siempre de un círculo social y político limitado.

\footnotetext{
${ }^{45}$ En mayo detuvieron a tres dirigentes bilbaínos del Partido Nacionalista Español y clausuraron el Club Alpino Laurak-bat, que les daba cobertura. Fueron detenidos Tomás Zubiría, José Luis Mogrovejo y Rafael Vierna Urquijo, este era el secretario provincial del PNE. PV, 21 y 24 de junio de 1932.

${ }^{46}$ González Cuevas, P. C.: Acción Española..., p. 175. A finales de septiembre, una comisión compuesta por Vegas, Vigón y Eliseda se trasladaron a Biarritz para entrevistarse con Calvo Sotelo; en la reunión acordaron formar una comisión presidida en el exterior por el conde de los Andes y en el interior por el marqués de Arriluce de Ibarra encargada de recaudar fondos. En la lista de donantes están J. T. Gandarias, marqués de Urquijo, condesa de Zubiría, conde de Aresti, viuda de Chávarri, marqués de Chávarri, marqués de Arriluce de Ibarra, marqués del Nervión, marqueses de Ibarra, marquesa de Mac Mahón.
} 
La política de acercamiento a los tradicionalistas fue seguida con entusiasmo en el ámbito local: El Pueblo Vasco, radicalizando su posición contra la República, publica diferentes artículos favorables a la unidad (Víctor Pradera), al tiempo que sigue atentamente esta orientación a nivel nacional ${ }^{47}$. El 30 de enero de 1933 tiene lugar un mitin de Renovación en el Euskalduna con intervención de Goicoechea y Sáinz Rodríguez, pero lo significativo no fue el contenido, ya que en lo sustancial seguía la doctrina tradicionalista, antiliberal, católica y antirrevolucionaria, sino otras dos cuestiones. En primer lugar, la defensa de las posiciones tradicionalistas sustentadas por Goicoechea ante algunas críticas realizadas por elementos monárquicos: «este hombre -decían-, es un tradicionalista más y nosotros permanecemos fieles a la política constitucional». El Pueblo Vasco replicó aduciendo la existencia de alianzas ocasionales entre conservadores y tradicionalistas durante el período de la Restauración, pero, sobre todo, argumenta, «están poco los tiempos para elegancias retrospectivas y purismos exigentes (...). Frente a la amenaza colectivista desaparecen diferencias que en otras condiciones de serenidad podrían no parecer accesorias... ${ }^{48}$.

El segundo aspecto que nos parece destacable de este acto fue el discurso de presentación que realizó Pilar Careaga, una de las personalidades más significativas del monarquismo vizcaíno, que defendía aún la posibilidad de unión con los nacionalistas:

«Esta agrupación que viene a acaudillar el señor Goicoechea nace como un paso ineludible para llegar a la unión de las derechas. Había una masa amorfa, desorientada y sin dirección. Hacía falta forjar el instrumento que recogiera a sus componentes dispersos, que los coordinara. Este organismo existe ya. Claro que la obra que nos hemos impuesto no está exenta de dificultades y que estas se complican en una región como esta donde entre las derechas hay puntos neurálgicos que conviene tratar con sumo cuidado. Me refiero a los nacionalistas, a quienes hemos de hacer comprender que no queremos una monarquía centralista, que queremos construir un Estado de nueva planta, instaurar un régimen monárquico federativo y hacerles comprender que la República masónica y demagógica podrá darles unas patria, pero es a cambio de que renieguen de Dios. El nacionalismo es también derecha, y con él tenemos en común lo que nos une en Dios y podemos tener también la patria y las instituciones si acertamos, repito, a hacernos oír y comprender» ${ }^{49}$.

${ }^{47}$ En diciembre da amplia cobertura a un ciclo de «conferencias tradicionalistas» celebradas en Madrid en las que intervinieron miembros de ambos partidos favorables a la unión como Esteban Bilbao y el dirigente de Renovación Goicoechea. PV, 12, 13, 18 diciembre de 1932.

${ }^{48}$ VG, 31-I-1933, «Jornada memorable» y «Nuevos tiempos».

${ }^{49}$ VG, 31-I-1933, «El banquete. Los brindis», p. 3.. 
Es decir, la derecha dinástica confía aún a comienzos de 1933 en la posibilidad de acuerdos con los nacionalistas, y aún no ha incorporado el antinacionalismo, el antiseparatismo a su discurso, algo que después será un elemento básico de este.

Durante los meses siguientes los actos de acercamiento a los tradicionalistas se suceden tanto en lo doctrinal como en lo electoral. Nuevo mitin en el mismo lugar, en este caso de los tradicionalistas, en protesta por la Ley de Congregaciones Religiosas, apoyo a la candidatura tradicionalista al Tribunal Constitucional, mitin y discursos de Bilbao y Urraca en Astigarraga el 7 de diciembre. En Bilbao, los contactos sostenidos por Areilza y el diputado tradicionalista Marcelino Oreja posibilitaron la creación del Centro Electoral Autónomo (CEA), un nuevo órgano de unión de las derechas con fines electorales que se mantendrá en los años posteriores pero limitado a dicho fin (nota: solo vigente en los períodos electorale ${ }^{50}$ ) y en Madrid se forma igualmente una oficina electoral, TYRE, a fines de marzo. El acercamiento culmina con la alianza electoral de cara a la elección general de noviembre de 1933, una elección a la que Renovación concurre en coalición con Acción Nacional dentro de un Frente de Derechas (bases de la coalición aprobadas el 14 de octubre). En la circunscripción de Vizcaya-capital la candidatura incluyó dos candidatos alfonsinos (Adolfo G. De Careaga y Pilar Careaga) y dos tradicionalistas (Luis Lezama-Leguizamón y Hermógenes Rojo) mientras que en la de la Provincia presentó dos candidatos uno de cada sector: Areilza y Oreja. «Candidatura Española y vascongada». El CEA dirigió los trabajos electorales ${ }^{51}$.

\section{La incorporación del antiseparatismo al ideario de la derecha}

En principio intentaron sumar al PNV a un bloque contrarrevolucionario sobre la base del catolicismo y el antimarxismo como temas comunes capaces de unir a toda la derecha («la unión sagrada de toda la derecha»). Pero las negociaciones con el PNV fracasaron a pesar de los esfuerzos de los coaligados a causa, según dijeron, del Estatuto. ${ }^{52}$ La negativa del PNV sumó además otro fracaso, pues La Gaceta del Norte, representante de un sector importante de los católicos, apoyó a los nacionalistas.

El rechazo de los nacionalistas por la cuestión del Estatuto fue posiblemente una excusa, puesto que la posición de la derecha dinástica respecto de aquel fue también un ejemplo de cautela y moderación. Un día antes de la

${ }^{50}$ El PV lo acogió con júbilo considerando que era un primer paso para dicha unión, PV, 5-2-1933.

${ }^{51}$ No obstante El Pueblo Vasco todavía sigue apelando a la unión de todas las derechas, y reproduce los discursos de Gil Robles, si bien sus mayores esfuerzos se dirigen a la unidad con el tradicionalismo.

${ }^{52} \mathrm{PV}, 14,15,18$ de noviembre de 1933. 
reunión en Pamplona de los ayuntamientos, El Pueblo Vasco (PV) expresó su opinión sobre el anteproyecto del Estatuto de las Gestoras: tras destacar la ausencia de mención «al espíritu religioso de nuestro pueblo» $\mathrm{y}$ «su constitución foral», rechazaba de manera matizada la atribución de competencias en materia de orden público y justicia, pero aprobaba las restantes, educación, obras públicas, sanidad y, especialmente, en lo referente a enseñanza. Su posición global no era negativa, pues la hacía depender de su aplicación e interpretación ${ }^{53}$. Esta posición fue la misma que mantuvieron en el plebiscito del 5 de noviembre de 1933, para el que recomendaron el voto favorable en un Manifiesto firmado por el conde de Superunda, Pilar Careaga, Juan de Aranceta, marqués de Lamiaco, Lorenzo Hurtado de Saracho, conde del Cadagua, Alfonso Alcalá Galiano, Jose M. ${ }^{a}$ de Areilza y Adolfo G. de Careaga ${ }^{54}$. Sin embargo, un sector de esta corriente representada por la Unión Patriótica y el Partido Nacionalista Español manifestaron su oposición frontal al Estatuto y pidieron el voto en contra ${ }^{55}$ También en el caso de los tradicionalistas el Estatuto provocó una división interna. Mientras los diputados Oreja y Beunza y sus dirigentes Julián Elorza y Pérez Arregui manifestaban su apoyo pidiendo el voto favorable en el plebiscito, los integristas desarrollaron una intensa campaña en contra desde las páginas de los periódicos La Constancia de San Sebastián y El Siglo Futuro de Madrid ${ }^{56}$. Ante la división, las autoridades del partido de las tres provincias adoptaron una solución de compromiso: aun siendo contrarios a su contenido, no aconsejan el voto negativo, pero tampoco «pueden obligar a sus afiliados al voto afirmativo al Estatuto» ${ }^{57}$.

Pero estas posiciones no fueron al parecer suficientes para atraer al PNV $\mathrm{y}$, constatada su negativa, la campaña buscó la movilización del electorado católico y conservador, y se responsabilizó a los nacionalistas de la división de las derechas frente a las izquierdas. Pero lo más significativo fue la incorporación del antiseparatismo como nueva bandera de propaganda y doctrina. Mientras el 21 de octubre el PV escribía que «hoy por hoy el principal enemigo es el marxismo», en el manifiesto publicado pocos días antes de la elección, cuando ya las negociaciones estaban rotas, incorporan a su programa el antiseparatismo: «Candidatura española y vascongada», «frente al marxismo, laicismo y separatismo ofrecemos españolidad, catolicidad y foralidad», «por Dios, por Vizcaya y por España -terminaba Pilar Careaga-, ¡Viva España!, ¡viva Vizcaya española!» ${ }^{58}$.

${ }^{53} \mathrm{PV}, 18-\mathrm{VI}-1932$, «Algunas consideraciones sobre el Estatuto».

${ }^{54} \mathrm{PV}, 27-\mathrm{X}-1933$.

${ }^{55} \mathrm{PV}, 28-\mathrm{X}-1933$, «Manifiesto». El periódico publicó ambos escritos pero explicando que no representaba su opinión. Hubo además otros sectores alfonsinos que criticaron este apoyo al Estatuto aunque sin hacerlo público. PlatA, G.: op. cit. p. 223.

${ }_{56} \mathrm{PV}, 25-\mathrm{X}-1933$.

${ }^{57} \mathrm{PV}, 26-\mathrm{X}-1933$.

${ }^{58}$ PV, 19-XI-1933, «Mitin en el Teatro Buenos Aires del Bloque de Derechas». 
Este fue un momento clave para el devenir de la derecha pues «la aceptación de la autonomía suponía contar con las aspiraciones de los otros; significaba también orientarse hacia una actuación política en el marco republicano (...). El rechazo significaba la opción por la intransigencia...» ${ }^{59}$. El PNV, con su maximalismo y la consideración del Estatuto como instrumento hacia la independencia, contribuyó a radicalizar la posición de las derechas ${ }^{60}$.

Tras las elecciones, RE quedará sola, fuera del ámbito de la CEDA, a merced por tanto de sus propias fuerzas y además afectada por una profunda división interna. La estrategia política de la CEDA durante el bienio 1934-1935, basada en la aceptación de la legalidad republicana, exigía «soltar amarras» con una derecha monárquica cada vez mas radicalizada y por supuesto con el carlismo; así es que, a partir de mayo de 1934, la coalición electoral que había concurrido a las elecciones generales quedaría rota y se dejaba a los monárquicos a merced de sus propias fuerzas. "Con la entrada de la CEDA en el Gobierno y el triunfo de este sobre la insurrección de octubre, el aislamiento político del alfonsismo llegó a su cenit. RE ofrecía una imagen de partido minoritario de extrema derecha ejerciendo una oposición a la República prácticamente testimonial» ${ }^{61}$.

Mientras tanto, las relaciones con los liberal-conservadores de la CEDA se rompieron; Renovación Española intentó aumentarlas con los tradicionalistas, proponiendo la creación de un órgano político común. Pero en el seno de la CT, los sectores mas proclives a la colaboración, perdieron posiciones: D. Alfonso Carlos, el regente, designaba como sucesor a un miembro ajeno a la línea sucesoria de Alfonso XIII y, sobre todo, el nombramiento de Fal Conde como Secretario general de CT, totalmente contrario a la unión, cortó de golpe todas las esperanzas puestas por los alfonsinos en la unión ${ }^{62}$.

Además de su aislamiento pronto aparecieron también síntomas de división política interna, planteándose un debate entre restauracionistas e instauracionistas (D. Alfonso o D. Juan), entre los partidiarios del uso de tácticas legales contra el Estado democrático y quienes apostaban por la lucha en todos los frentes, incluido el uso de la fuerza, entre neoconservadores y neotradicionalistas. Goicoechea y Calvo Sotelo representaban estas corrientes internas. El primero consiguió mantener el control del partido pero ello no

\footnotetext{
${ }^{59}$ PLATA, p. 223.

${ }^{60}$ El recelo de las derechas lo expresó Calvo Sotelo en el Congreso de los Diputados en diciembre de 1935 en la forma siguiente: «Cuando al Estado español se le pidió el Estatuto Vasco (...) es indudable que hubo vascos que honradamente creían que el Estatuto iba a ser una fórmula de nueva vida económica o autónoma en el seno de la unidad española; pero hay otros vascos, los dirigentes del nacionalismo, que indudablemente no piensan así y anhelan el Estatuto como instrumento que dé paso a la independencia total». PV, 7-XII-1935. También Derecha Autónoma Vasca denunciará esta valoración del nacionalismo.

${ }^{61}$ Ver GIL, Conservadores..., p. 197.

${ }^{62}$ Ibidem, p. 200.
} 
fue obstáculo para que Calvo Sotelo aumentara lentamente su actividad e influencia ${ }^{63}$.

RE en Vizcaya siguió con entusiasmo la política de colaboración y acercamiento no solo político sino ideológico con el carlismo, al tiempo que ahondaba las diferencias con el nacionalismo. Respecto de los primeros, el 5 de diciembre de 1933, el Centro Electoral Autónomo organizó un acto conjunto en Archanda para celebrar los resultados electorales en el que los oradores fueron Areilza por los alfonsinos y Urraca Pastor por los carlistas. Los dos pronunciaron un encendido discurso común contra la democracia y el parlamentarismo. Igualmente a comienzos de 1934, El Pueblo Vasco declaraba que «ison tan escasas las diferencias entre los principios que defiende el partido tradicionalista y nosotros...!» ${ }^{64}$. Respecto del nacionalismo, el artículo de Areilza publicado en El Pueblo Vasco el 5 de enero iba mas allá en su diagnóstico: la defección del PNV del campo de las derechas no es un problema puntual que se solucione con una alianza electoral, sino la consecuencia «de la falta de una conciencia nacional vigorosa que tenga fe en la misión histórica de España. Este es el problema». Tampoco es un problema local, «el separatismo -dirá unos meses más tarde-, es el problema principal de España», «ni las persecuciones religiosas, ni la crisis de autoridad son comparables al nacionalismo, pues no se puede soñar para España una misión histórica sino tiene bien asentado el principio de unidad nacional» ${ }^{65}$. Se comprende cómo el nacionalismo se convierte en categoría esencial en la ideología de este sector.

En los meses siguientes los acontecimientos sociales y políticos aumentan el radicalismo ideológico: en abril, Areilza defiende la democracia orgánica, un Estado fuerte frente a la República (evoca con nostalgia la dictadura de Primo de Rivera), un sistema basado, según él, en «principios decadentes» como la democracia, el liberalismo y el sufragismo. El conflicto de los ayuntamientos vascos durante el verano ${ }^{66}$, el movimiento revolucionario de octubre, los asesinatos del falangista Manuel Carrión en San Sebastián en septiembre y Marcelino Oreja en octubre ${ }^{67}$, añadieron nuevos motivos de confrontación con los nacionalistas a quienes acusaron de participación en ellos $^{68}$. Pero también contra la República por su debilidad en la represión:

\footnotetext{
${ }^{63}$ Ibidem, pp. 208-213.

${ }^{64} \mathrm{PV}, 2-\mathrm{II}-1934$.

${ }^{65}$ PV, 23-III-1905, Conferencia en San Sebastián invitado por la Liga Regionalista de Guipúzcoa.

${ }^{66}$ PV, 2-IX-1934, Manifiesto «A la opinión Vascongada», y PV, 4-IX-1934, «Mitin en Carranza de Unión Vascongada».

${ }^{67}$ PV, 15-IX-1934, «Guerra Civil», art. de Maeztu, y PV, 11-XI-1934, «Ante el asesinato de Oreja».

${ }^{68}$ «Los sucesos de octubre hicieron infranqueable el abismo que separaba al PNV de la derecha católica, monárquica y tradicionalista, cuyos portavoces insistieron en "las nefandas
} 
exaltación de la unidad de España frente al laicismo, el separatismo y el marxismo, necesidad de un Estado fuerte que garantice el orden, ensalzamiento del ejército y Guardia Civil como garantes del orden y la unidad de la patria ${ }^{69}$.

En resumen, a partir de las elecciones de noviembre de 1933, la derecha vizcaína católica, monárquica y tradicionalista asume los postulados contrarrevolucionarios mas radicales.

Estas posiciones ideológicas y políticas fueron acompañadas por cambios en la organización. RE como partido se adecuaba a los círculos oligárquicos dinásticos de Vizcaya, pero su imagen no encajaba con sectores de opinión de monarquismo más tibio o con actitudes menos radicales frente al régimen. De ahí el nacimiento de «Unión Vascongada», una nueva organización con la que operarían desde entonces en el ámbito de la provincia. La Unión «constituyó el mayor éxito organizativo de la derecha españolista, descontando la Comunión Tradicionalista, durante la II República...» ${ }^{70}$ presidida por Luis Urresti e integrada por las personalidades monárquicas más significadas pertenecientes a la burguesía industrial, consiguió constituir comités y centros en muchos pueblos utilizando las antiguas redes caciquiles de la antigua Liga Monárquica, representó por ello un esfuerzo por ampliar su base social tradicional a sectores de la clase media y del ámbito rural. En la Asamblea celebrada en julio de 1934 asistieron representantes de 77 municipios. Pero los dirigentes eran los mismos, al igual que sus principios ideológicos: catolicismo, orden, autoridad, antimarxismo, antiseparatismo y antiliberalismo ${ }^{71}$. Este cambio estuvo acompañado también por esfuerzos en la actividad de propaganda mediante la realización de mítines con mayor frecuencia durante los años siguientes, con discursos muy radicalizados en contra del régimen republicano y sobre la base de los principios ideológicos enunciados ${ }^{72}$.

concomitancias del nacionalismo con la revolución" y en su deslizamiento del campo de las derechas al de las izquierdas», GRANJA, J.: op. cit., p. 504. El Pueblo Vasco publica en los meses de octubre y noviembre numerosos artículos acusando al nacionalismo de connivencia con estos acontecimientos, especialmente con la revolución de octubre.

${ }^{69}$ A finales de octubre y noviembre se suceden los homenajes de todo tipo organizados por los monárquicos al ejército por su papel en la represión de la revolución. Para no ser reiterativo basta evocar el artículo de Evaristo Churruca del 18-II-1935 publicado con el expresivo título «España Unida y en Orden», en el cual ensalza la unidad de España y al Ejército como su garante. PV, 18-II-1935.

${ }^{70}$ Plata, La derecha..., p. 76 y ss.

71 «El objetivo de Unión es servir el principio de unidad nacional». Lorenzo Villalonga en el mitin de Unión en Carrranza. PV, 4-VI-1935. Sobre la Unión, Plata, pp. 76-79.

${ }^{72}$ En estos dos años realizan muchos mítines pero su contenido resulta de escaso interés al repetir los principios a los que hemos aludido. 


\section{Un sector de centro en el seno de la derecha}

En el ámbito local, Renovación (o Unión Vascongada) era la única organización existente en el campo de la derecha; en el nacional la CEDA era la fuerza mayoritaria. Sus posiciones eran bien distintas, pues la estrategia y táctica de la segunda eran posibilistas, accidentalista respecto del régimen republicano y aceptaban la legalidad; RE era intransigente y rechazaba la legalidad y legitimidad de aquel. La ideología les aproximaba más pero la CEDA profesaba principios menos excluyentes, más moderados. En cuanto a su base social, RE se asentaba en las clases altas, en la aristocracia y en limitados sectores de la alta burguesía, especialmente en la de Vizcaya ${ }^{73}$, mientras que la CEDA tenía en las clases medias su apoyo principal. La afiliación era reducida sobre todo comparada con la CEDA y CT. RE fue incapaz de competir con la CEDA por el apoyo de la clase media o el pequeño campesino: partido de élites al viejo estilo, nunca un partido de masas.

Dicho esto, resulta sorprendente la escasa o casi nula implantación de la CEDA en Vizcaya, de manera que en el seno de la derecha local las únicas opciones organizadas no nacionalistas eran la alfonsina y la carlista, ambas muy radicalizadas (respecto de los católicos intransigentes, reparten sus apoyos entre todas las fuerzas, incluidos nacionalistas y, especialmente, carlistas). Debemos suponer que estas fuerzas no representaban toda la derecha, el problema es que no podemos cuantificarla al no estar organizada ni concurrir a los procesos electorales. Tan solo detectamos algunos intentos de organización.

El primero fue la inauguración de unos locales en Bilbao el 25 de agosto de 1934 con las siglas de Acción Popular (partido origen de la CEDA, AP) que fueron asaltados por la izquierda. Debió existir algún comité, pero la única muestra que dio de actividad fue la elaboración de un manifiesto con motivo de los sucesos de octubre: «Acción Popular de Vizcaya a la opinión pública» ${ }^{74}$. Desde luego el documento nos parece muy significativo por su actitud moderada, contemporizadora, matizada, especialmente con los nacionalistas, a quienes los monárquicos habían implicado en la sublevación, lo que desencadenó una campaña antinacionalista furibunda, radical. Para AP solo participaron algunos sectores no controlados del nacionalismo, «pero sus masas no tienen culpa». Lo cierto es que no fue más que un propósito inicial que no se mantuvo, pues en la campaña electoral de febrero de 1936 su discurso fue idéntico al de la derecha radical.

${ }^{73}$ A la fiesta celebrada en el Marítimo el 24 de agosto asistieron unas 300 personas que representaban la práctica totalidad de la oligarquía financiera e industrial de Vizcaya. PV, 25-VIII-1935, «Comentarios del día».

${ }^{74} \mathrm{PV}, 30-\mathrm{X}-1934$. 
Tras la inauguración, solo encontramos muestra de actividad de cara a las elecciones de 1936 y ahora con el nombre Acción Popular Vascongada, presidida por Miguel Goldaracena (fue el candidato de Acción en la coalición electoral). También las Juventudes se organizaron con este objetivo en enero de 1936. Desplegaron una campaña electoral intensa y celebraron mítines conjuntos con las demás fuerzas coaligadas.

\section{Derecha Vasca Autónoma}

El día 21 de octubre de 1935 realizó su presentación pública en el frontón Urumea de San Sebastián un nuevo partido, Derecha Vasca Autónoma, que estuvo presentada por su presidente Juan Pablo de Logendio, y por Jose M. ${ }^{a}$ Gil Robles, jefe de la CEDA. En enero de 1936 aparece como miembro de esta José Orueta, un bilbaíno liberal avanzado, autor de una conocida obra, Fueros y autonomía ${ }^{75}$, cuyo título y contenido nos hace pensar en su influencia en la definición del ideario. El discurso de Logendio resulta toda una sorpresa por su moderación, realismo y capacidad de análisis ${ }^{76}$ :

1. En primer lugar se refirió al momento y contexto de su nacimiento, un momento caracterizado por la división de las derechas y la falta de organización:

«Nació en los momentos siguientes a la revolución de octubre. Horas de intensa gravedad para la vida española, graves también en la política del País Vasco (...), un momento además en el cual la política del País estaba controlada por el movimiento nacionalista vasco gracias al volumen de las masas que le acompañaban.

Éramos muchos, sin embargo, los vascos que permanecíamos apartados de aquel movimiento por las hondas discrepancias ideológicas que de él nos separaban, por los errores que advertíamos en su táctica y por la desorientación y los equívocos que acusábamos en su dirección.

(...) Por otra parte el auge del movimiento nacionalista había introducido la división más profunda entre las derechas del país, que estaban divididas en bandos antagónicos...».

2. Necesidad de organizar a la derecha no «sobre la base de los bandos existentes sino partiendo de elementos independientes no adscritos a aquellos, capaces de encauzar los problemas por vías de moderación y serenidad».

75 Orueta, José de: Fueros y Autonomía. Proceso del Estatuto Vasco. Nueva Editorial. San Sebastián, 1934.

${ }^{76}$ VG, 22-X-1935, «Derecha Vasca Autónoma». 
3. El País Vasco constituye una región con personalidad propia y diferenciada por su lengua e historia que el Estado debe reconocer

4. Hasta ahora han prevalecido las soluciones maximalistas e intransigentes, irrealizables: reintegración foral o independencia:

«unos se dicen partidiarios de la plena reintegración foral, y claro está que nada hacen por conseguirla porque la saben imposible, y los otros les acusan de insinceros. Pero entre los acusadores los hay que son separatistas y no lo proclaman. También son insinceros. Y entre unos y otros, los que se dicen fueristas y no lo son y los que son separatistas y no lo dicen, hay una masa sana, un pueblo honrado que a ninguno cree y marcha cansada por el camino del escepticismo (...)».

5. Es necesario por ello impulsar una política posibilista, moderada, eficaz, capaz de dar soluciones reales al problema:

«Frente a todo lo que consiguieron los viejos partidos con una táctica posibilista dentro de la legalidad ¿qué se ha conseguido de tangible para el país con la otra táctica triunfante desde hace unos años? Táctica posibilista y política posibilista...».

6. El autonomismo es la solución del problema vasco y por eso constituye la principal seña de identidad del nuevo partido frente a los que reivindican la reintegración foral (carlistas) o los que persiguen la independencia (nacionalistas).

«Derecha Vasca es un partido auténticamente autonomista. (...) Creemos que dentro de un régimen de autonomía y dentro siempre de la nación española puede hallarse solución a la mayoría de los problemas vascos (...)».

7. Unidad de todos los vascos en la defensa de la autonomía:

«Sobre las bases de estas líneas generales se podría hacer un programa mínimo sobre el cual lograr la restauración de la unidad espiritual del país dolorosamente quebrada».

8. Unión de las derechas:

«Por ahora nos limitamos a exponer un programa y hacer un llamamiento a la armonía del país. Un programa común que pueda servir de lazo de unión de todos los partidos de derecha. Que pueda acabar con esa tirantez ineficaz de las derechas del País Vasco»: 
La aparición de Derecha Vasca como partido vinculado a la CEDA era un soplo de aire fresco en la política local caracterizada por la crispación y la polarización, y era también una alternativa distinta en el seno de una derecha (un sector conservador) representada por elementos monárquicos cuya radicalidad no conectaba con la opinión de algunos sectores de ella más moderados y transigentes; unos grupos que, como señalaba Logendio, estaban retraídos y desorganizados. La presencia de Orueta, un liberal avanzado y autonomista convencido, pero retraído desde la Dictadura, los representa. Aunque nació en San Sebastián, fue también el único intento de organización de un partido vasco común a las tres provincias. En este sentido desconocemos si iniciaron contactos con otra organización próxima como era Acción Popular de Bilbao (Acción Popular Vascongada) o si hicieron algún trabajo de propaganda.

El futuro, sin embargo, no respondió a las expectativas con las que nació. La polarización de la vida política española dificultaba la suerte de estas opciones, de modo que la proximidad de las elecciones generales empujó a todas las corrientes, tanto de derechas como de izquierdas, hacia la formación de bloques radicalmente enfrentados. También en el plano local, el frente contrarrevolucionario que se formó aglutinó a todos los grupos de la derecha excepto al PNV: en Vizcaya, el 12 de enero de 1936 un comunicado daba cuenta de la unión de RE, Unión Vascongada, Comunión Tradicionalista y Acción Popular Vascongada. Igualmente, en Guipúzcoa, Derecha Vasca se incorporó a la misma coalición el 18 de enero ${ }^{77}$.

La campaña electoral que realizó el Bloque se definió por su componente negativo y radical: antirrevolución, antimarxismo, antilaicismo y antiseparatismo, exaltación del patriotismo español, del catolicismo y beligerancia extrema contra el PNV «como cómplice activo de la revolución». «O eliges la España gloriosa, católica, tradicional y cristiana, o la anti España, descuartizada, masónica, judía, roja» ${ }^{78}$. Era un discurso dogmático, extremista, muy alejado de las posiciones ideológicas de Derecha Vasca.

Los resultados en España, favorables al Frente Popular, produjeron el abatimiento de la derecha a pesar del aumento del voto respecto de la elección de 1933, especialmente en el caso de RE, cuyos resultados fueron peores. «El 16 de febrero -decía Calvo Sotelo-, constituye una fecha fatal y profunda en la historia de España, algo mas denso y grave que el 14 de abril $\gg^{79}$. No obstante, en el País Vasco los resultados fueron positivos para el frente, pues el aumento de votos fue muy significativo, mientras que, por el Arlade.

${ }^{77}$ PV, 10-I-1936. Los representantes de Derecha Vasca fueron José Orueta y José M.a

${ }^{78}$ Un resumen de los temas de la campaña en GrANJA, pp. 547-548. El PV publica los discursos de múltiples mítines, comunicados y manifiestos, pero todos ellos repiten con escasas variaciones los temas que hemos señalado.

${ }^{79} \mathrm{PV}, 6-\mathrm{IV}-1936$. 
contrario, el PNV, contra los cuales habían dirigido el grueso de la campaña, perdió muchos apoyos (lo cierto es que el aumento no se tradujo en escaños ${ }^{80}$. El resultado fue aún más meritorio teniendo en cuenta que los partidos coaligados «hicieron cada uno la guerra por su cuenta», como se quejaba El Pueblo Vasco $^{81}$, dándose el caso de los dos candidatos que concurrieron por Vizcaya-provincia, los cuales se combatieron entre sís ${ }^{82}$; también el abandono de los carlistas de Guipúzcoa de cara a la segunda vuelta obligó a Derecha Vasca a seguirle muy a su pesar ${ }^{83}$. Sin duda, los partidos derechistas locales estaban totalmente subordinados a sus organizaciones nacionales lo que condicionaba sus valoraciones y orientaciones. En el momento del abandono, Derecha ratificó su deseo de seguir las mismas orientaciones de su nacimiento, esto es, el autonomismo dentro de la moderación: «Unión de todos los católicos, armonía de todos los vascos ${ }^{84}$.

Las elecciones de 1936 fueron la última oportunidad para esta derecha extrema, radical, autoritaria y antiliberal, de subvertir el régimen republicano utilizando la legalidad. El 8 de junio era clausurado el centro de Renovación Española en Bilbao; se encontró una pistola y fueron detenidos 15 socios y su presidente Julio Serrano ${ }^{85}$. Era evidente que, tras las elecciones, la mayoría de sus afiliados solo pensaban en derribarlo por la fuerza ${ }^{86}$.

\section{CONCLUSIONES}

1. La derecha vizcaína no tradicionalista estaba fragmentada en varios sectores: monárquicos, nacionalistas y católicos intransigentes.

2. La Dictadura destruyó las bases sobre las que se había asentado la hegemonía de los liberal-monárquicos en la provincia. Ciertos grupos fueron conscientes de ello y propusieron soluciones alejadas del liberalismo.

\footnotetext{
${ }^{80}$ Ver resultados en GRANJA, pp. 548 y ss.

${ }^{81} \mathrm{PV}, 2$-III-1936, «Comentarios».

${ }^{82}$ Fue el caso de Gaytán de Ayala por la Comunión Tradicionalista y Martínez de las Rivas por Renovación, GRANJA, p. 560, nota 107. La alianza de la derecha fue muy precaria: las negociaciones de la CEDA con los alfonsinos fueron muy difíciles por la división interna de estos y sobre todo por las exigencias de Calvo Sotelo. El período electoral sirvió para sacar a la luz las profundas divisiones entre las distintas fracciones derechistas. Pasadas estas quedaron otra vez desunidos. Ver en GIL, pp. 232-238.

${ }^{83} \mathrm{PV}, 28-\mathrm{II}-1936$.

${ }^{84}$ Ibidem.

${ }^{85}$ PV, 9-VI-1936, «Clausura del Centro de Renovación».

${ }^{86}$ Plata, p. 259.
} 
3. La orientación de aquellos hacia el autoritarismo y el antiliberalismo se acentuó durante la II República como consecuencia de los acontecimientos y de una política que, en su opinión, atacaba las bases del orden social. Al principio, enarbolaron la bandera del catolicismo, pero luego añadieron otras como el marxismo, la crisis de autoridad, la democracia, etc., hasta desembocar finalmente en posiciones antiliberales y antirrevolucionarias, es decir, tradicionalistas.

4. Los monárquicos hicieron esfuerzos por unir la derecha. Una vez fracasados, el antinacionalismo y antiseparatismo se convirtirían en el eje principal de su ideario, realzando en cambio la unidad de España.

5. Sorprende la falta de arraigo en la provincia de la CEDA. Solo a finales de 1935 se constituye Derecha Autónoma Vasca. Su discurso era moderado, abierto y posibilista pero, como señalaba El Pueblo Vasco, no estaban los tiempos para opciones de centro. La polarización existente les empuja, al igual que a la CEDA, a entrar en el frente contrarrevolucionario formado para concurrir a las elecciones generales de 1936. 